\title{
Research on the Business English Training Model within MBA Program
}

\author{
Natalia Yankovskaya \\ The Russian Presidential Academy of National Economy and Public Administration \\ Correspondence concerning this article should be addressed to Natalya Yankovskaya, Department of \\ Business Communication and English language, Institute of Business Studies, The Russian Presidential \\ Academy of National Economy and Public Administration, 82, Vernadsky Avenue Moscow, Russian \\ Federation, 119571.E-mail: yankovskaya-nb@ranepa.ru
}

\section{Olga Neklyudova}

The Russian Presidential Academy of National Economy and Public Administration

\begin{abstract}
Correspondence concerning this article should be addressed to Olga Neklyudova, Department of Business Communication and English language, Institute of Business Studies, The Russian Presidential Academy of National Economy and Public Administration, 82, Vernadsky Avenue, Moscow, Russian Federation, 119571.E-mail: nekludova_olga@mail.ru
\end{abstract}

The paper presents a brief summary of the research on the Business English training model within MBA program students. This study is devoted to the problem of developing a professional foreign language communicative competency of MBA program participants. A particular feature of additional MBA qualification is its international status which presupposes that its graduates (midlevel and top managers) should realize their professional tasks in a foreign language. The analysis of literary works follows in order to find out if activity and competency-based approaches are chosen as instructional bases for developing the model of a business foreign language training that can ensure building a professional foreign language communication competency of the MBA program participants. The result of the study is the model of a business foreign language training that guarantees the development of a professional foreign language communication competency within the process of obtaining additional professional MBA qualification and that includes the following structural components: learning objective, content, a set of forms of organizing the learning process and technological description of each of the five modules. The next part of the paper suggests the result of the research based on testing of the business foreign language training model that guarantees the development of a professional foreign language communication competency when achieving additional professional MAS qualification including a description of the process and the results of assessing the developed dyadic model. The testing consisted of summative and formative assessment and was carried out in the the Russian Presidential Academy of National Economy and Public Administration in several stages (from 1999 to 2007 and then again from 2010 to 2014). When analyzing the results of assessing the dyadic model both the data obtained in control groups (teaching based on the traditional system) and in experimental groups (teaching based on the developed model) were compared. On the basis of the studies the conclusion was made that business English language training, aimed at the development of professional foreign communicative competence of MBA students, organized in accordance with our didactic model, can achieve the goal of real-verbal communication in English in professional environment (business English should become a tool for solving professional problems), and fully meet the needs of students.

Keywords: Business English training model, professional foreign language communicative competency, dyadic model, learning process, forming experiment, summative assessment 
In the 90-ies of the XX century the demand of Russians for foreign language skills escalated. This fact is related with social and economic changes, with the modification of the role of our country in the international arena, and the actualization of the society need for specialists with the knowledge of a business foreign language in accordance with internationally accepted standards (e.g., Business English Certificate - BEC). Integration of Russia into the global economy and new information technologies require modern managers not only to be able to translate professional literature, but to have a real skill of verbal communication in a foreign language in order to render educational programs of other countries accessible, and provide a possibility to have training in foreign companies and participate in co-projects.

These studies consider the problem of an efficient spoken foreign language training for adults, professional foreign language training for students, business foreign language for senior high school students and course participants, specific aspects of distance education, as well as issues of professional language education and preparation of educational programs within the system of professional education for specific specialists.

Development of a professional foreign language communicative competency during the process of obtaining an additional MBA qualification (Master of Business Administration) has never served as an object of a special study.

This study is devoted to the problem of developing a professional foreign language communicative competency of MBA program participants. A particular feature of additional MBA qualification is its international status which presupposes that its graduates (mid-level and top managers) should realize their professional tasks in a foreign language. Along with this, the case study revealed that the foreign language training process within MBA program is not focused on a competency approach and modern ways of training for adults; the level of foreign language skill of the most part of the program graduates does not conform to current requirements, i.e. a real oral communication in a foreign language when solving professional problems (Evenko, 2005). Basically, a general educational orientation of foreign language teaching is manifest in professional training, when a foreign language mastering serves as a goal in itself, and is not aligned with a professional training and professional orientation of education which consider a business foreign language to be a means for solving professional tasks. This fact is conditioned by the absence of a science-based model of a business foreign language training which is focused on a competencybased approach and allows students to develop a foreign language communicative competency in a real oral activity when they solve professional tasks. The performed analysis showed that the development of a professional foreign language communicative competency in the additional professional education system is a current problem.

A theoretical analysis of studies and practice of developing a professional foreign language communicative competency in the additional professional education system helped to reveal the following contradictions:

- A contradiction between the need of managers who know a foreign language (English, mainly) for practicing, and inadequacy of the existing system of a business foreign language training in institutions for an additional professional education and modern requirements;

- A contradiction between managers' need for developing a foreign language communicative competency as a means for solving professional tasks and a traditional approach to a business foreign language training which is not focused on a competency-based approach and modern ways of getting education for adults.

The problem is to sort out the contradictions with the help of a theoretical and methodological substantiation, elaboration and experimental check of a business foreign language training model that guarantees the development of a professional foreign language communicative competency of MBA participants focused on a competency-based approach, taking into account particular features of adults' learning activity and conforming to the requirements of the MBA additional qualification. The study focused on the development of a professional foreign language communicative competency of students within the additional professional education system. So, under the subject of the research we understand here the development of a professional foreign language communicative competency of participants during the process of obtaining the MBA additional qualification.

Throughout the research we pursued the goal of elaborating, theoretically substantiating, and experimentally checking a business foreign language training model that guarantees the development of a professional foreign language communicative competency of participants during the process of obtaining the MBA additional qualification.

The research question we faced with the current study stems from the following hypothesis. The level of a professional foreign language communicative competency of MBA participants will correspond to students' needs and requirements of the MBA additional qualification, if the following holds true:

- objectives of a foreign language teaching agree with those of MBA training, and a foreign language is a means for solving professional tasks;

- educational process is based on an activity and competency-based approach supported by a content-related integration of educational, 
social, and professional aspects of students' activity in the form of the full-time and distant education combined.

In accordance with the subject, objective, and hypothesis hereof the following tasks are defined:

1. To perform a theoretical analysis of the status of the problem of the development of a professional foreign language communicative competency within the additional professional education system.

2. To define the degree of elaboration of the problem of the development of a professional foreign language communicative competency during the process of obtaining the MBA additional qualification.

3. To formulate theoretical and methodological grounds in order to define a business foreign language training model that guarantees the development of a professional foreign language communicative competency during the process of obtaining the MBA additional qualification.

4. To elaborate a dyadic model that guarantees a real oral communication of MBA participants in a foreign language when they solve professional tasks.

5. To define a complex of organizational and pedagogical conditions for the realization of the dyadic model of the development of a professional foreign language communicative competency during the process of studying under the MBA program, and to perform an experimental study related with the testing of the elaborated dyadic model.

\section{Materials and Methods}

The elaboration of a business foreign language training model that guarantees the development of a professional foreign language communicative competency of the MBA program participants and its experimental study were based on the carried out study of the problem of the development of a professional foreign language communicative competency within the additional professional education system on the basis of a characteristic of main trends and approaches to the additional professional education, defined requirements to modern additional professional education as a whole, and its particular features that influence on the preparation of educational programs, and the MBA program in particular.

The study helped to define a place of business education within the additional professional education system, as well as main trends of its development and a brief characteristic of the MBA program.
The study revealed the following trends of the development of the additional professional education: a humanistic nature of education, a long-life education, focus on a personality development, satisfaction of educational needs in the sphere of solving professional tasks, focus on a competency-based approach, an open nature of education environment, focus on the use of developed information technologies. The description of education results in the language of competencies is one of the most important tasks of modern additional professional education (Rogers, 1983).

The analysis of different ways of organizing the additional professional education led to the conclusion that one of the most promising forms is an open additional professional education, because it to the utmost conforms to the revealed trends of the development of the additional professional education and is focused on a competency-based approach.

The following ideas and principles of an educational process organization in an open additional professional education serve as grounds for the definition of a business foreign language training model that guarantees the development of a professional foreign language communicative competency of the MBA program participants: a competency-based approach, an idea of integration of three environments (i.e. learning, professional, and social), the synthesis of three approaches to education (i.e. andragogical, learnercentered, and contextual), an idea of the combination of activity technologies (i.e. informational, pedagogic, and organizational and communicative), because they meet modern requirements to a professional education, take into account peculiar features of adults' learning activity, and contribute to the satisfaction of their educational needs (Schennikov, 2002; Kay Thorne, 2004, pp. 50-70; Kolb and Fry, 1975, pp. 33-57; Rogers, 1986).

The analysis of foreign language training approaches and study results allowed us to reveal a number of effective ideas and inventions that formed the basis of the elaboration of a business foreign language training model:

1. A communicative approach implies the realization of students' needs, i.e. their performance of a real communicative activity which helps them to master a foreign language (L. Sh. Gegechkory, I. Yu. Shekhter, V. V. Petrusinskiy, G. A. Kitaygorodskaya, et al.).

2. An address to intellectual and personal reserves of a student, a revitalization of cognitive processes, a positive influence on emotional sphere, a fatigue relief (G. Lozanov).

3. A transfer from informational to active forms and methods of education: learning, activating, intensive, playing, with elements of problematicity 
and an investigator's search (A. A. Verbitskiy, A. A. Leontiev, T. V. Kudryavtsev, A. M. Matyushkin, et al.).

4. The development of skills to use a foreign language in a certain social context and the use a linguistic and cross-cultural material (A. Gumpers, T. M. Dridze, D. Khaims, et al.).

5. A situational approach aimed at the development of oral speech based on examples fixed in typical communicative situations (A. A. Alkhazishvili, V. A. Bukhbinder, I. A. Zimnyaya, E. I. Passov, et al.).

6. An idea of a phrasal stereotype (I. M. Berman, N. I. Zhinkin, et al.).

7. An integrity in the development of a foreign language communicative competency that implies the absence of a distinction between phonetic, grammatical, and lexical aspects of a language.

8. Models of the development of a professionally oriented communication in the English language of specialists from various spheres in the system of a long-life professional education (T. V. Aldonova, A. Ya. Gaisina, A. K. Krupchenko, G. P. Savchenko, T. M. Saltykova, V. Ph. Tenishcheva, G. G. Khantseva, N. A. Shishkina, M. K. Shlangman, et al.).

Moreover, the analyzed ideas and approaches cannot be used as an integral dyadic model of the development of a professional foreign language communicative competency of MBA program participants due to a specific nature of this educational program and particular features of its consumers.

\section{Model Description}

Activity and competency-based approaches are chosen as instructional bases for developing the model of a business foreign language training that can ensure building a professional foreign language communication competency of the MBA program participants. The above approaches define aims, structure, content, forms, methods, and techniques of a business foreign language training for managers within the MBA Program Retraining Course.

The highlighted particular features of the adults' learning activity - such as learning from experience (R. Revans, Pedler, et al.), cyclical sequence of learning activities when a student passes all the stages of the learning cycle (Kolb and Fry), developmental type of activity based on analyzing the difficulties in professional activity and further drifting to a reflexive space (V. Davydov, G. Shchedrovitsky, et al.), integrating learning and professional activities (A. Verbitsky, S. Shchennikov, et al.), integrating learning and social activities (A. Savostyanov, V. Slobodchikov, Ye. Komrakov, et al.) - allowed us to specify the requirements to organizing the learning process of building a professional foreign language communication competency of the MBA program participants (Kolb \& Fry, 1975, pp. 33-57).

The following particular features of an open additional professional education, that influence the development of a business foreign language training model for the MBA program participants are highlighted:

- The learning process is based on individual work of participants;

- Learning activity is carried out within the professional and social activities of participants;

- Modular organization of a learning process;

- Combination of developmental pedagogical and information-communication technologies;

- Learning activity aims at solving professional tasks;

- Providing the possibility of an individual learning path;

- Obligatory face-to-face meetings;

- Communicative principle of organizing the learning content and interaction of the learning process participants.

The following form of organizing the learning process of building professional foreign language communication competency is defined as exhibiting the most promise - integrating the in-class and distance learning, in a similar way to an open additional professional education model - the International Institute of Management LINK that allows to orient the learning process toward a competency-based approach.

The result of the study is the model of a business foreign language training that guarantees the development of a professional foreign language communication competency within the process of obtaining additional professional MBA qualification and that includes the following structural components: learning objective, content, a set of forms of organizing the learning process and technological description of each of the five modules.

The learning objective is to acquire a foreign language communication competency demonstrated as actual verbal communication in professional activity. Analyzing the competencies required from the MBA Program graduates (according to the state requirements) allowed to single out the communication competencies of an MBA Program graduate based on which the model of a foreign language communication competency is built. This model is the basis for picking out standard professional tasks implemented by a manager in an actual verbal communication in a foreign language:

1. Making and maintaining contacts (Making Contacts);

2. Providing description of functional roles and job description (Responsibilities and Job Description); 
3. Presenting a company (a strategy, a mission, company's targets, organization structure etc.), a product (services), a project (Company Presentation);

4. Communicating during a business trip (in an airport, in a hotel, in a restaurant etc.) (Going on Business);

5. Communicating during meetings (Meetings);

6. Making phone calls (Telephoning);

7. Negotiating (Negotiating);

8. Maintaining business correspondence (Business Correspondence);

9. Searching and analyzing business information in English (periodical publications, Internet, TV, radio etc.) (Business Information Scanning and Analysis);

10. Company Performance Appraisal; Personnel Appraisal;

11.Providing reports, business plans, business process analysis results (Reporting; Business Planning);

12. Taking into account cultural context in crosscultural interaction (Cross Cultural Interaction).

Learning content as the set of singled out standard professional tasks is structured as five modules each of which corresponds to a certain level of a foreign language communicative competency development (orientating, operational, operational-artistic, artistic and creative) and includes four types of verbal activity (speaking, reading, listening, and writing). Standard tasks are solved in each module but at different levels of communicative competency development. At certain levels of communicative competency development, some of them become principal while the others play propaedeutic or supporting role.

Set of forms of organizing the learning process includes the following: initial and adaptation faceto-face meeting, independent work with the learning kit (with teacher's support), analytical and practical face-to-face meeting and examinations (presentation and final examination according to the BEC format) depending on the level (preliminary, vantage and higher). The main set of forms that consists of the independent work with the learning kit (with teacher's support) and analytical and practical face-to-face meeting has four implementation cycles.

Technological description of each of the five modules includes targets, main tasks, specific forms, methods and means of organizing learning process that ensure best combination of group, individual and collective forms of learning (group forms playing the leading role) and are aimed at developing a foreign language communication competence.

The model justifies the necessity to use new learning technologies - imitation and role-playing, information, problem-searching, communicative and case studies, as well as defines the boundaries of using pedagogical technologies during a face-to-face and distance interaction.

Theleadingroleis playedbyactiveteachingmethods, such as small-group discussions, brainstorming, analyzing specific situations or role-playing usage of which is not limited to face-to-face interactions and is supported by using modern information technologies. The combination of teaching methods provides intensive interaction between a teacher and a student and among students.

Description of the model includes the process of choosing the teaching aids taking into account selecting a multi-channel principle of an educational material retention (aids in hard copy, audio- and video aids, computer and telecommunication means, office equipment, etc.).

The dyadic model of a business foreign language training describes specific features of a teacher's activity when studying the modules. A teacher functions as a learning process coordinator and as an integrator of all the learning materials and teaching aids. A distinctive feature of the distance learning is shown that a teacher uses specific methods and aids not only during face-to-face interaction but also during the virtual interaction together with information and communication technologies.

When developing the model the following organizational and pedagogical conditions of effectively implementing a business foreign language training model were defined that ensure the development of a professional foreign language communication competency of MBA program participants: organizational and administrative support, constant support of participants' learning activity by a teacher, feedback and monitoring of a learning activity, instructional support (availability of an adequate learning kit which is the main content bearer at an independent work stage) and a technical and technological, information and staff support.

\section{Results}

The next stage is a pilot testing of a business foreign language training model that guarantees the development of a professional foreign language communication competency when achieving additional professional MAS qualification including a description of the process and the results of assessing the developed dyadic model.

The pilot testing consisted of summative and formative assessment and was carried out in The Russian Presidential Academy of National Economy and Public Administration in several stages (from 1999 to 2007 and then again from 2010 to 2014). 
When analyzing the results of assessing the dyadic modelboth the data obtained in controlgroups (teaching based on the traditional system) and in experimental groups (teaching based on the developed model) were compared. Upon the completion of the experiment the comparative analysis of the data obtained before and after it was carried out. The dynamics of achieving a foreign language communication competence was monitored in accordance with the singled out communication competence development levels.

The experiment consisted of the following stages:

Stage 1. Entrance testing of the English language proficiency level.

Stage 2. Preparing for carrying out a formative experiment and its direct implementation.

Stage 3. Stage-by-stage and final diagnostics of a foreign language communication competency following the implementation of the developed instructional model.

For assessing the effectiveness of the developed instructional model the following indicators were used:

- Degree of satisfaction of the MBA Program business foreign language learners;

- Self-assessment of the learners' ability to actually communicate in English in the professional environment;

- Self-testing of the learning results;

- Dynamics of developing a foreign language communication competency (using tests);

- Level of an actual verbal communication in English in a professional environment (analyzing the activity results by levels).

The target of the summative assessment was to define the level of foreign language communication competency development of the MBA participants. The results of the ascertaining experiment confirmed that all verbal activity types of the participants are poorly developed.

Methods of the summative assessment:

1. For the questionnaire survey the following questionnaires were used - questionnaire of a Business English Program participant, selfassessment questionnaire, and the Program Graduate Questionnaire.

2. The testing method allowed to appraise the degree of the development of reading and listening skills, as well as the level of an active vocabulary and grammar knowledge.

3. Questioning, discussions and interview methods were used for appraising the degree of verbal English communication skills development, as well as for specifying the learning needs of the participants.

4. The method of assessing statistical data (in particular, testing results).
The following criteria were used as characterizing the English language skills:

1. authenticity of a foreign language behavior to situations and tasks of a professional communication;

2. degree of a functional adequacy;

3. a linguistic correctness.

The above can be combined as one criterion adequacy of a verbal behavior. The degree of the criterion prominence was assessed in conditional points:

5 - a complete adequacy of a verbal behavior;

4 - adequacy of a verbal behavior with minor deviations;

3 - major deviations from a criterion;

2 - inadequacy of a verbal behavior.

The qualitative indicator is calculated using the formula shown below:

$$
\mathrm{K}=\frac{N_{5} \times 5+N_{4} \times 4+N_{3} \times 3+N_{2} \times 2}{N \times 5}
$$

where $N_{5}$ - number of participants who receive a score of 5 ;

$N_{4}$ - number of participants who receive a score of 4;

$N_{3}$ - number of participants who receive a score of 3 ;

$\mathrm{N}_{2}$ - number of participants who receive a score of 2 ;

$N$ - total number of participants.

All the data on self-assessment and assessment of the results of learning in the experimental work are calculated using the qualitative indicator.

The entrance testing included listening tasks (20\% weight in the general assessment), assessing the level of vocabulary and grammar knowledge (50\%) and reading (30\%).

The percentage of successfully completed tasks was calculated in the part of Listening as follows:

$$
\boldsymbol{P}_{1}=\frac{\mathrm{N}^{\prime \prime} \mathrm{x} 20 \%}{\boldsymbol{N}^{\prime}}
$$

where $N^{\prime}$ is the total number of tasks;'

$N^{\prime \prime}$ is the number of successfully completed tasks.

The percentage of successfully completed tasks checking vocabulary and grammar communication skills was calculated as follows:

$$
\boldsymbol{P}_{2}=\frac{\mathbf{N}^{\prime \prime \prime} \mathbf{x} \mathbf{5 0} \%}{\boldsymbol{N}^{\prime}}
$$

The percentage of successfully completed tasks in the part of Reading:

$$
\boldsymbol{P}_{3}=\frac{\mathbf{N}^{\prime \prime} \times \mathbf{3 0} \%}{\boldsymbol{N}^{\prime}}
$$

The Placement test lasted 1.5 hours. Placement test results in Table 1 show weak skills in listening, active vocabulary, and reading in English, as well as poor grammar skills. 
Table 1

The results of the placement test

\begin{tabular}{lccccc}
\hline Parameters & \multicolumn{2}{l}{ distribution of students according to their score, number of people } & $\begin{array}{c}\text { quality } \\
\text { indicator, \% }\end{array}$ \\
\hline & 5 & 4 & 3 & 2 & \\
\hline Listening & 0 & 12 & 95 & 19 & 58,8 \\
\hline $\begin{array}{l}\text { Vocabulary and } \\
\text { grammar }\end{array}$ & 0 & 10 & 102 & 14 & 59,3 \\
\hline Reading & 0 & 12 & 94 & 20 & 58,7 \\
\hline Speaking & 0 & 7 & 97 & 22 & 57,6 \\
\hline
\end{tabular}

The candidates were awarded marks by the examiner after the conversation. The quality indicator of the performed speaking skills was low on the results of entry interviews (57.6\%). Most of the candidates refused to do written tasks because of the inability to write in English.

Thus, the results of entrance tests led to the conclusion that students had unacquired all communication activities in the English language.

The purpose of the formative experiment consisted of the organization of educational process on the development of professional foreign language communicative competence of MBA program students. The process was organized in accordance with the research program developed by the author based on scientific didactic model.

The regular comparisons of the data obtained in control and experimental groups were carried out. At the end of the experiment a comparative analysis of the data obtained before and after the experiment was carried out. We monitored the dynamics of foreign language communicative competence in accordance with the selected levels of communicative competence development.

Methods of forming experiment:

1. Questionnaires

2. Enquiries and interviews were used to identify the expectations of the students, the difficulties in the educational process.

3. Testing (midline and final) marked the current level of foreign language communicative competence.

4. Analysis of the written work, projects, case studies, business games.

5. Monitoring the decision of communicative tasks by students when performing professionally oriented communicative exercises in English.

6. Evaluation of the test results before the experiment, when going from module to module and after conducting the forming experiment.

7. Comparative analysis was used to compare the results obtained during the experiment in control and experimental groups.
Stage 1 - Placement test in English.

Stage 2 - preparation for the forming experiment and its implementation.

Stage 3 - step-by-step and final diagnostics and gradual increment of foreign language communicative competence in accordance with its level of development. It was the embodiment of the developed model of professional foreign language communicative competence of the MBA students.

During the experiment, we could verify how the level of foreign language communicative competence has been changed - from roughly trial to the operational and creative, etc. Business English training was organized in experimental groups in accordance with the developed didactic model, and in control groups using the traditional system.

One of the most important indicators of consistent with the model of the didactic needs of the consumer, the requirements to the further vocational education and the level of training in the MBA program is the level of satisfaction of students with the process of Business English teaching.

The number of students who are satisfied with the process of Business English teaching (the sum of those who are completely satisfied and rather satisfied) in the control groups is $36 \%$. The majority $(41 \%)$ believe that they are partially satisfied. The proportion of those who are partially or completely unsatisfied is $15 \%$.

The number of students from the experimental groups who were satisfied with the process of $\mathrm{BE}$ teaching is $87 \%$, there were no fully dissatisfied, while the share of those who are partially satisfied or dissatisfied is $11 \%$.

During the experiment, data were obtained for selfassessment ability of mastering the English language for communication in a professional environment; the results of self- diagnostics of Business English students, the diagnostics was held to determine the level of foreign language communicative competence in control and experimental groups by testing. After that, a comparative analysis of the self-diagnostics 
Table 2

Data obtained for self-assessment ability

\begin{tabular}{lcccc}
\hline Indicator & \multicolumn{3}{c}{ Before study, \% } & In the end of study, \% \\
\cline { 2 - 5 } & $\begin{array}{c}\text { Control } \\
\text { group }\end{array}$ & $\begin{array}{c}\text { Experi- } \\
\text { mental } \\
\text { group }\end{array}$ & $\begin{array}{c}\text { Control } \\
\text { group }\end{array}$ & $\begin{array}{c}\text { Experi- } \\
\text { mental } \\
\text { group }\end{array}$ \\
\hline $\begin{array}{l}\text { sure that there } \\
\text { are abilities }\end{array}$ & 4 & 2 & 9 & 16 \\
\hline $\begin{array}{l}\text { think that there } \\
\text { are abilities }\end{array}$ & 10 & 9 & 32 & 46 \\
\hline $\begin{array}{l}\text { Average abilities } \\
\begin{array}{l}\text { insignificant } \\
\text { abilities }\end{array}\end{array}$ & 53 & 51 & 41 & 28 \\
\hline $\begin{array}{l}\text { There are no } \\
\text { abilities }\end{array}$ & 13 & 16 & 4 & 14 \\
\hline
\end{tabular}

in solving professional problems after training and the analysis of diagnosis of the teacher were held, as well the analysis of delayed learning outcomes for the course of business English.

\section{Discussion}

On the basis of pilot studies the conclusion was made that business English language training, aimed at the development of professional foreign communicative competence of MBA students, organized in accordance with our didactic model, can achieve the goal of realverbal communication in English in professional environment (business English should become a tool for solving professional problems), and fully meet the needs of students, as evidenced by the following results:

- a high degree of satisfaction with teaching business English in the experimental groups (the number of students who are satisfied with the learning process, is $87 \%$ compared with $36 \%$ in the control group);

- a significant increase in self-esteem of their own abilities to the actual verbal communication in English in a professional environment at the end of training, compared with a starting self-esteem;

- a high level of self-test of capability to real verbal communication in English in a professional environment that is gradually formed in the process of implementation of a didactic model. The self-estimation difference is much higher in the experimental groups. If on approximate and operational levels of foreign language communicative competence the difference of selfestimation assessment in control and experimental groups was on average $10 \%$, on the operational and creative, artistic and creative level, this difference increased to $25 \%$;

- stable rise of foreign language communicative competence at the expense of a consistent transition in the learning process of the indicative level of foreign language communicative competence to operational, operational and creative (quality figure is much higher from module to module in the experimental groups, according to the results of final control is $87 \%$ compared from $60 \%$ in the control group);

- the adequacy of self-assessment by students to the ability to real verbal communication in English in professional environment, which was confirmed by the diagnostics held by the teacher;

- the demand of English as a means of solving professional problems in cross-cultural communication situations (for $62 \%$ of students in the experimental groups compared with $12 \%$ in the control).

\section{Conclusion}

The study confirmed the hypothesis and allowed the following conclusions:

1. On the basis of the characteristics of the main directions and approaches to the further professional education the modern requirements to the further professional education as a whole and particularly affecting the construction of educational programs, including the MBA program, were emphasized. The place of business education in the further professional education and the main trends of its development were determined. A brief description of the MBA program was given.

2. The expectations of consumers of educational services of the MBA program to learning outcomes were determined, including professional foreign language communicative competence. The features of educational activity of adults, affecting the development of the business model of learning a foreign language, providing professional development of foreign language communicative competence of students of the MBA program were emphasized.

3. Specific characteristics of the further professional education affecting the construction of a model of business foreign language teaching of the MBA program students were determined. The most perspective form of organizing the educational process for the development of professional foreign language communicative competence the integration of full-time and distance learning, 
allowing to focus on competence approach was determined.

4. The approaches to the organization of educational process on the development of professional foreign language communicative competence in the system of the further professional education managers were theoretically grounded relying on the competence and activity approaches, meaningful integration of academic, social and professional aspects of students activities, and complex of didactic, organizational and pedagogical conditions.

5. The model of a business foreign language teaching, providing professional development of foreign language communicative competence of students of the MBA program, built on the basis of a combination of forms of full-time and distance learning, and included the goals of foreign language teaching the managers as a means of realization of their professional activity; educational content, structured on the module basis; technological description of the program modules were developed.

6. The levels of development of foreign language communicative competence (tentative, operational, operational and creative, creative) were determined; and the complex of typical tasks was suggested ensuring the acquisition of business foreign language content by MBA students.

7. The complex of educational process organization forms, appropriate to goals and content of foreign language teaching in the process of obtaining the additional qualification of MBA was established.

The obtained results open perspectives for further research on this issue and the creation of teaching materials, teacher training, development of organizational procedures and administrative support, developing of supporting Internet media etc.

\section{References}

Evenko, L. I. (2005). The impact of the continuing learning concept on MBA program. In Business education in continuing learning systems. St. Petersburg, Russia: Piter.

Thorne, K. (2004). Blended learning. London, UK: London and Sterling.

Keynes, M. (1988). The centre for critical thinking. Retrieved from www.criticalthinkung.org/icat.html Kolb, D., \& Fry, R. (1975). Towards an applied theory of experimental learning. In C. Cooper (Ed.), Theories of Group Process (pp. 33-57). London, UK: John Wiley.

Ur, P. (1996). A course in language teaching. Cambridge, UK: CUP.

Rogers, A. (1986). Teaching adults. Buckingham, UK: Open University Press.

Schennikov, C. A. (2002). Open distance education. Moscow, Russia: Nauka. 